\title{
Anesthetic Management of Children with Larsen Syndrome
}

Ayşe Çiğdem TÜTÜNCÜ, Pınar KENDIGELEN, Atasoy GÜRLEVIK, Gülçin KARACAN, Güner KAYA

Department of Anaesthesiology and Reanimation, İstanbul University Cerrahpaşa School of Medicine, İstanbul, Turkey

\section{ABSTRACT}

Larsen Syndrome is the rare inherited disease of defect in collagen formation. It is characterized by facial and extremity abnormalities. Spine anomalies scoliosis, kyphosis, wedge vertebrae, and spondylosis also have been described in this syndrome. A 7 month old, male, 3750 gr. boy with a diagnosis of Larsen syndrome was scheduled for bilateral inguinal hernias operation under general anesthesia. The preoperative examination revealed knee joint dislocations, clubfoot and unusual face (flat faces, high palate). Long QT syndrome was detected and propranolol medication was started preoperatively. The patient had severe scoliosis, thorax deformities with pectus carinatus. Following standart monitors placement, anesthesia was induced sevoflurane/air, intubation facilitated with rocuronium $(0.6 \mathrm{mg} / \mathrm{kg})$ and then caudal analgesia was performed. The intraoperative course uneventful. The hemodynamic status and rhythm was stable during surgery and in the postoperative period. At the end of the surgery neuromuscular blockage was reversed with sugammadex. The child was totally awake without any respiratory difficulty except with minimal substernal retraction and there was no motor block. The patient was sent to the recovery room and he was discharged home following day without any complication. In conclusion, patients with Larsen syndrome have issues pertinent to anesthesiology relating to the musculoskeletal, respiratory, cardiac and neurological systems.

Keywords: Child, anesthesia, Larsen syndrome

\section{Introduction}

Larsen syndrome is a rare genetic disease associated with defect in collagen formation. It is characterized by facial and extremity abnormalities. Spinal anomalies such as scoliosis, kyphosis, wedge vertebra, and spondylosis have also been described in this syndrome $(1,2)$.

In this report, we present a case with Larsen syndrome, which was scheduled to undergo inguinal hernia surgery; in addition, the anesthetic management of this syndrome is discussed.

\section{Case Report}

A 7-month-old male infant, weighing $3750 \mathrm{~g}$, diagnosed with Larsen syndrome was scheduled to undergo surgery for bilateral inguinal hernia under general anesthesia. Physical examination showed a small for age child. A preoperative examination revealed knee joint dislocations and clubfoot. The unusual appearance was characterized by flat facies and high palate, depressed nasal bridge, widely spaced eyes, and prominent forehead. The patient had severe thorax deformities with pectus carinatum and small rib cage with prominent lower rib margins (Figure 1). A generalized hypotonia was detected during the neurological examination and severe scoliosis was observed in the spinal column. He had not have a previous surgery. His routine preoperative laboratory tests including complete blood count and renal and hepatic function tests were within normal limits. His preoperative electrogram revealed LQTS with a $0.47 \mathrm{~ms} \mathrm{QT}_{\mathrm{c}}$ interval, and propranolol medication was started preoperatively after consulting a pediatric cardiologist. 


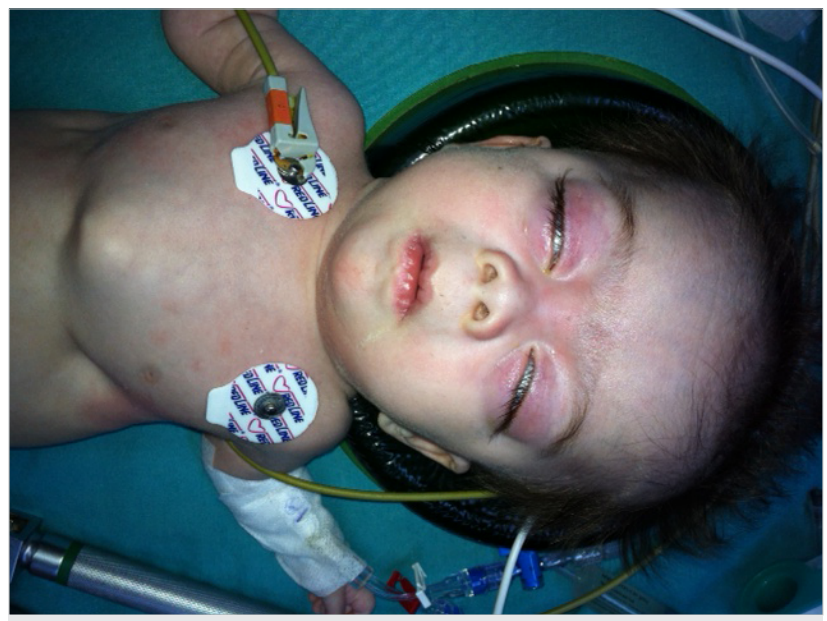

Figure 1. General appearance of patient's face and thorax

Following ECG, oxygen saturation, end tidal carbon dioxide, and noninvasive arterial monitoring, general anesthesia was induced with air/oxygen and sevoflurane gradually decreased the concentration from $4 \%$ to $2 \%$ and maintained with the same agents after confirming proper ventilation, intubation facilitated with rocuronium $(0.6 \mathrm{mg} /$ $\mathrm{kg}$ ). There was subglottic stenosis and the Cormack-Lehane score was observed to be IV. The patient could intubate with tube of no: 3 , 5. A caudal epidural block (7 $\mathrm{mg}$ bupivacaine $/ 4 \mathrm{ml} 0.9 \% \mathrm{NaCl}$ ) was performed for postoperative analgesia after the intubation. The intraoperative course was uneventful. The hemodynamic status and rhythm was stable during the surgery. The mean arterial pressure was $85 / 50 \mathrm{mmHg}$ and the heart rate was between 140 and $155 / \mathrm{min}$. At the end of the surgery, neuromuscular blockage was reversed using sugammadex $(2 \mathrm{mg} / \mathrm{kg})$. The child was completely awake without any respiratory difficulty; however, he showed minimal substernal retraction without any motor block. The patient was transferred to a recovery room and he was discharged the following day without any complication.

\section{Discussion}

Patients with Larsen syndrome may require surgery for multiple orthopedic abnormalities (1). Anesthesia management of this syndrome has many potential problems such as airway difficulty, laryngotracheomalacia, pre- and postoperative respiratory problems, congenital cardiac abnormalities, and difficult venous access. Airway, respiratory, and cardiac problems may have life-threatening consequences $(1,2)$. Narrowing at the distal part of the respiratory system and malacia in the upper and lower airways were the most frequent reported abnormalities of this syndrome. Laryngomalacia, tracheomalacia, bronchomalacia, subglottic stenosis, and restrictive lung disease may worsen the anesthesia management and prognosis. Air leak at the $20-30 \mathrm{~cm} \mathrm{H}_{2} 0$ pressures could lower the incidence of post-intubation edema.
The thorax deformities may provide additional risk factors for patients. Atelectasis and pneumonia are possible outcomes of malacia and deformities $(2,3)$. Frequent pulmonary toilet and chest physiotherapy are suggested during the perioperative and postoperative period.

The presented case exhibited subglottic stenosis; therefore, we used a small intubation tube. A short course neuromuscular blocker was preferred to prevent prolonged effect. Following tracheal extubation, mild croup was detected, and this was treated with nebulized air.

Air leak at $20-30 \mathrm{~cm} \mathrm{H}_{2} 0$ is recommended in these children to prevent high incidence of croup. Sugammadex was used to reverse neuromuscular block; a successful recovery was observed in a short time period. We prefer using sugammadex to provide quick relief from neuromuscular block and improve muscle strength. The results regarding the prolongation of the $\mathrm{QT}_{c}$ interval with sugammadex are conflicting. Although some rare studies have been reported about prolongation of the QT ${ }_{c}$ interval with sugammadex, we did not observe any ECG changes. Knowledge of the effects of inhalation anesthetics on $\mathrm{QT}_{c}$ interval is also conflicting, and their exact clinical effects are unclear. There are several reports which state that desflurane prolong QT ${ }_{c}$ interval more than sevoflurane. Sevoflurane may prolong the $\mathrm{QT}_{c}$ interval in healthy volunteers. Many drugs may prolong the $\mathrm{QT}_{c}$ interval in patients but the torsade genecity is associated with transmural dispersion of depolarization (TDP), and torsade only occurs when TDP increases (4). Although sevoflurane could prolong the $\mathrm{QT}_{c}$ interval, it did not affect TDP. Another drug, thiopental, is reported to prolong the QT interval; nevertheless, it reduces TDP and can therefore be used safely for anesthesia induction and maintenance in children with LQTS (5).

\section{Conclusion}

Anesthesia for children with Larsen syndrome can be hazardous. Although a few reports about anesthesia management, difficulty in airway, risk of malignant hyperthermia, and sudden cardiac arrest have been reported, a number of multisystem abnormalities relating to skeletal, respiratory, cardiac, and neurological systems necessitate careful evaluation and attention during both perioperative and postoperative periods in these patients.

Informed Consent: Informed consent was obtained from patients who participated in this study.

Peer-review: Externally peer-reviewed.

Author Contributions: Concept - G.K., A.C.T.; Design - A.C.T.; Funding - G.K., A.C.T., P.K.; Data Collection and/or Processing - A.C.T., G.K., P.K., A.G., G.K.; Analysis and/or Interpretation - G.K.; Literature Review A.C.T., P.K., A.G.; Writing - A.C.T., P.K.; Critical Review - G.K.

Conflict of Interest: No conflict of interest was declared by the authors.

Financial Disclosure: The authors declared that this study has received no financial support. 


\section{References}

1. Tobias JD Anesthetic implications of Larsen syndrome. J Clin Anesth 1996; 8: 255-7 [CrossRef]

2. Malik P, Choudhry DK. Larsen syndrome and its anaesthetic considerations. Anaesth Intensive Care 2003; 31: 217-20.

3. Critchley LA, Chan L. General anaesthesia in a child with Larsen syndrome. Paediatr Anaesth 2002; 12: 632-6.
4. Kiel EA, Frias JL, Victorica BE. Cardiovascular manifestations in the Larsen syndrome. Pediatrics. 1983; 71: 942-6.

5. Dahl V, Pendeville PE, Hollmann MW, Heier T, Abels EA, Blobner M. Safety and efficacy of sugammadex for the reversal of rocuronium-induced neuromuscular blockade in cardiac patients undergoing noncardiac surgery. Eur J Anaesthesiol 2009; 26: 874-84. [CrossRef] 